\title{
Type of Reportable Event ICSR Terminology
}

National Cancer Institute

\section{Source}

National Cancer Institute. Iype of Reportable Event ICSR Terminology. NCI Thesaurus.

Code C54591.

Terminology used in Individual Case Safety Reports to specify the type of reportable event, section $\mathrm{H} 1$ of FDA MedWatch Form. 